\title{
Endoscopic ultrasound fine-needle aspiration characteristics of primary adenocarcinoma versus other malignant neoplasms of the pancreas
}

\author{
Veronika Gagovic $M D^{1}$, Bret J Spier $M D^{1}$, Ryan J DeLee $M D^{1}$, Courtney Barancin $M D^{1}$, Mary Lindstrom $\mathrm{PhD}^{3}$ \\ Michael Einstein $M D^{1}$, Siobhan Byrne $M D^{1}$, Josephine Harter $M D^{2}$, Rashmi Agni $M D^{2}$, Patrick R Pfau MD', \\ Terrence J Frick $M D^{1}$, Anurag Soni MD ${ }^{1}$, Deepak V Gopal MD FRCPC FACP FACG FASGE ${ }^{1}$
}

V Gagovic, BJ Spier, RJ DeLee, et al. Endoscopic ultrasound fine-needle aspiration characteristics of primary adenocarcinoma versus other malignant neoplasms of the pancreas. Can J Gastroenterol 2012;26(10):691-696.

BACKGROUND: Endoscopic ultrasound (EUS) with fine-needle aspiration (FNA) is often used to assist in the evaluation of pancreatic lesions and may help to diagnose benign versus malignant neoplasms. However, there is a paucity of literature regarding comparative EUS characteristics of various malignant pancreatic neoplasms (primary and metastatic).

OBJECTIVE: To compare and characterize primary pancreatic adenocarcinoma versus other malignant neoplasms, hereafter referred to as nonprimary pancreatic adenocarcinoma (NPPA), diagnosed by EUSguided FNA.

METHODS: The present study was a retrospective analysis of a prospectively maintained database. The setting was a tertiary care, academic medical centre. Patients referred for suspected pancreatic neoplasms were evaluated. Based on EUS-FNA characteristics, primary pancreatic adenocarcinoma was differentiated from other malignant neoplasms. The subset of other neoplasms was defined as malignant lesions that were 'NPPAs' (ie, predominantly solid or solid/cystic based on EUS appearance and primary malignant lesions or metastatic lesions to the pancreas). Pancreatic masses that were benign cystic lesions (pseudocyst, simple cyst, serous cystadenoma) and focal inflammatory lesions (acute, chronic and autoimmune pancreatitis) were excluded.

RESULTS: A total of 230 patients were evaluated using EUS-FNA for suspected pancreatic mass lesions. Thirty-eight patients were excluded because they were diagnosed with inflammatory lesions or had purely benign cysts. One hundred ninety-two patients had confirmed malignant pancreatic neoplasms (ie, pancreatic adenocarcinoma [ $n=144]$, NPPA $[n=48])$. When comparing adenocarcinoma with NPPA lesions, there was no significant difference in mean age $(\mathrm{P}=0.0675)$, sex $(\mathrm{P}=0.3595)$ or average lesion size $(\mathrm{P}=0.3801)$. On average, four FNA passes were necessary to establish a cytological diagnosis in both lesion subtypes $(\mathrm{P}=0.396)$. Adenocarcinomas were more likely to be located in the pancreatic head $(\mathrm{P}=0.0198)$, whereas masses in the tail were more likely to be NPPAs $(\mathrm{P}=0.0006)$. Adenocarcinomas were also more likely to exhibit vascular invasion ( $\mathrm{OR} 4.37 ; \mathrm{P}=0.0011$ ), malignant lymphadenopathy $(\mathrm{P}=0.0006)$, pancreatic duct dilation (OR 2.4; $\mathrm{P}=0.022)$ and common bile duct dilation (OR 2.87; P=0.039).

CONCLUSIONS: Adenocarcinoma was more likely to be present in the head of the pancreas, have lymph node and vascular involvement, as well as evidence of pancreatic duct and common bile duct obstruction. Of all malignant pancreatic lesions analyzed by EUS-FNA, 25\% were NPPA, suggesting that FNA is crucial in establishing a diagnosis and may be helpful in preoperative planning.

Key Words: Adenocarcinoma; Endoscopic ultrasound; Fine-needle aspiration; Malignant neoplasm; Nonprimary pancreatic adenocarcinoma; Pancreas
Les caractéristiques de l'aspiration à l'aiguille d'un adénocarénome primitif sous écho-endoscopie par rapport à d'autres néoplasmes malins du pancréas

HISTORIQUE : L'aspiration à l'aiguille (AA) sous écho-endoscopie (ÉES) contribue souvent à l'évaluation des lésions pancréatiques et peut être utile pour diagnostiquer un néoplasme bénin plutôt que malin. Cependant, il existe peu de publications sur les caractéristiques comparatives des ÉES de divers néoplasmes pancréatiques malins (primitifs et métastatiques).

OBECTIF : Comparer et caractériser les adénocarcinomes pancréatiques primitifs par rapport à d'autres néoplasmes malins, désignés ci-après par le terme adénocarcinome pancréatique non primitif (APNP), diagnostiqué par AA sous ÉES (AA-ÉES).

MÉTHODOLOGIE : Les chercheurs ont mené la présente analyse rétrospective à partir de la base de données prospective d'un centre universitaire de soins tertiaires. Les patients aiguillés en raison d'une présomption de néoplasmes du pancréas ont subi une évaluation. D'après les caractéristiques de l'AA-ÉES, les chercheurs ont distingué l'adénocarcinome pancréatique primitif des autres néoplasmes malins. Le sous-groupe d'autres néoplasmes était défini comme des lésions malignes, les APNP (surtout sous forme solide ou solide et kystique d'après l'apparence de l'ÉES et les lésions malignes primitives ou les lésions métastatiques du pancréas). Les chercheurs ont exclu les masses pancréatiques sous forme de lésions kystiques bénignes (pseudokyste, kyste simple, cystadénome séreux) et de lésions inflammatoires focales (pancréatite aiguë, chronique et auto-immune).

RÉSULTATS : Les chercheurs ont évalué un total de 230 patients par AA-ÉES en raison d'une présomption de lésions causées par une masse pancréatique. Ils ont exclu 38 patients parce qu'ils présentaient des lésions inflammatoires ou avaient des kystes purement bénins. Cent quatre-vingtdouze patients présentaient des néoplasmes pancréatiques malins confirmés (c.-à-d., adénocarcinome pancréatique [n=144], APNP [n=48]). Lorsqu'ils comparaient l'adénocarcinome aux lésions d'APNP, les chercheurs ne remarquaient aucune différence significative de l'âge moyen $(\mathrm{P}=0,0675)$, du sexe $(P=0,3595)$ ou de la dimension moyenne des lésions $(P=0,3801)$. En moyenne, il a fallu exécuter quatre $\mathrm{AA}$ pour parvenir à un diagnostic cytologique dans les deux sous-types de lésion $(\mathrm{P}=0,396)$. Les adénocarcinomes étaient plus susceptibles de se trouver à la tête du pancréas $(\mathrm{P}=0,0198)$, tandis que les masses de la queue du pancréas étaient plus susceptibles d'être des APNP $(\mathrm{P}=0,0006)$. Les adénocarcinomes étaient également plus susceptibles de présenter une invasion vasculaire (RRR 4,37; $\mathrm{P}=0,0011)$, une lymphadénopathie maligne $(\mathrm{P}=0.0006)$, une dilatation du canal pancréatique (RRR 2,4; $\mathrm{P}=0,022$ ) et une dilatation du canal cholédoque (RRR 2,87; $\mathrm{P}=0,039)$.

CONCLUSIONS : L'adénocarcinome était plus susceptible d'être présent à la tête du pancréas, de s'associer à des ganglions lymphatiques et à une atteinte vasculaire, de même qu'à des manifestations d'obstruction du canal pancréatique et du canal cholédoque. Parmi toutes les lésions pancréatiques malignes analysées par AA-ÉES, $25 \%$ étaient des APNP, laissant supposer le caractère crucial de l'AA pour établir un diagnostic et son utilité potentielle lors de la planification préopératoire.

${ }^{1}$ Division of Gastroenterology and Hepatology, Department of Medicine; ${ }^{2}$ Department of Pathology $\mathcal{E}$ Laboratory Medicine; ${ }^{3}$ Department of Biostatistics, University of Wisconsin School of Medicine $\mathcal{E}$ Public Health, Madison, Wisconsin, USA

Correspondence: Dr Deepak V Gopal, Division of Gastroenterology and Hepatology, University of Wisconsin School of Medicine E Public Health, Suite 4000 UW MFCB, 1685 Highland Avenue, Madison, Wisconsin 53705-2281, USA. Telephone 608-263-4033, fax 608- 265-5677, e-mail dvg@medicine.wisc.edu

Received for publication August 1, 2011. Accepted February 20, 2012 
$\mathrm{M}$ ass lesions of the pancreas represent benign and malignant neoplasms of the exocrine and endocrine tissues, in addition to metastatic disease. Previous studies report that endoscopic ultrasound (EUS) fine-needle aspiration (FNA) is $80 \%$ to $90 \%$ sensitive and nearly $100 \%$ specific for the diagnosis of pancreatic malignancy (1-4). Most pancreatic mass lesions are due to primary adenocarcinoma; approximately $10 \%$ to $15 \%$ are due to other lesions including cystic neoplasms or neuroendocrine tumours.

Obtaining a histopathological diagnosis of pancreatic mass lesions is important because other types of carcinoma may be more amenable to therapeutic intervention and have distinctly different survivability (5). In addition, therapeutic algorithms may differ based on pathological diagnosis. Once the FNA suggests malignancy, being able to identify specific EUS characteristics differentiating pancreatic adenocarcinoma from nonprimary pancreatic adenocarcinoma (NPPA) may further support a specific diagnosis and minimize uncertainty. Moreover, differentiating the type of malignant lesion determines the intervention and prognosis and it is important that this is accomplished accurately. In addition, some centres rely on FNA for all pancreatic mass lesions, while others are more selective in requesting FNA only in nonoperative candidates or for more unusual lesions. Therefore, there may be considerable utility and a need to define EUS features for detecting primary pancreatic adenocarcinoma versus NPPA.

The primary aim of our study was to compare primary pancreatic adenocarcinoma versus NPPA diagnosed by EUS-FNA in an attempt to identify EUS characteristics that can aid the endosonographer in differentiating between the two. Furthermore, we characterized what types of NPPA mass lesions arise from or metastasize to the pancreas.

\section{METHODS}

\section{Study design and patients}

The present study was a retrospective analysis of a prospectively collected database of patients who underwent EUS-FNA for a suspected pancreatic neoplasm between January 2004 and June 2009. The study received institutional review board approval and informed procedural consent was obtained from all patients.

Patients were referred based on previous radiographic imaging with a computed tomography scan demonstrating a mass lesion arising in the head, uncinate process, body or tail of the pancreas. The study cohort was limited to patients with solid or mixed solid/cystic pancreatic mass lesions, which was defined by EUS characteristics and the performance of $>1$ FNA pass. Purely benign cystic lesions (ie, simple cysts, pseudocysts, serous cystadenomas) and mass lesions secondary to focal acute or chronic pancreatitis of benign etiology and autoimmune pancreatitis, were excluded from analysis. The study cohort was further restricted to include patients with an FNA diagnosis that was definitive for or suspicious of malignancy. Cases that were suspicious for malignancy were subsequently confirmed by pathology on surgical resection or surgical biopsy or, in certain cases, follow-up FNA or EUS-guided core biopsy. Malignant lesions were defined as primary pancreatic adenocarcinoma versus NPPA, which are other solid or mixed solid/ cystic neoplasms that are primary or metastatic. With the above criteria applied, 192 malignant pancreatic neoplasms in 230 patients initially referred for EUS were analyzed.

\section{Procedural information}

Examinations under moderate conscious sedation consisting of intravenous midazolam and fentanyl, occasionally requiring droperidol or promethazine as adjunct sedation, were performed by one of three experienced endosonographers. Moderate conscious sedation was administered under an approved University of Wisconsin (Madison, Wisconsin, USA) institutional anesthesiology and gastroenterology protocol.

EUS examination was initially completed using a radial echoendoscope (GF-UM130 or GF-UE160, Olympus, USA) for evaluation and staging of target pancreatic lesions. Subsequently, a curvilinear echoendoscope (GF-UC140P-ALK5, Olympus) was used to evaluate and perform FNA of suspicious lesions. FNA was performed via standard technique using a 22-or 25-gauge needle (Echotip, Wilson-Cook, USA). Generally, a 22-gauge needle was used first. A 25-gauge needle was selected in cases of poor initial cellular return. A 19-gauge FNA needle (Quick-Core, Wilson-Cook, USA) was used in cases for which core biopsy was required. Immediate onsite cytopathology interpretation was available in all cases, either by the cytopathologist present or the presence of a cytology team member, such as a fellow trainee or technician, for assessment of specimen adequacy and direct, live video streaming of the cytology slide sample to the cytopathologist. For each procedure, the total number of FNA passes was recorded. The obtained sample was then passed to a member of the cytopathology team who then expressed the material onto glass slides (6). Both air-dried and alcohol-fixed smears are typically prepared. Air-dried slides were stained with Hema-Diff (Nova-Ultra, IHC World Life Sciences Products and Services, USA) and reviewed immediately to provide a preliminary diagnosis. The number of cells per slide and their representation of the target organ/lesion sampled were used to determine the adequacy of the slide. On completion of the procedure, the slides were taken to the laboratory for final processing, additional staining, and final detailed interpretation and reporting by the cytopathologist.

\section{Variables collected}

After identifying the study cohort of 192 patients, patient age and sex, along with EUS findings and pathology results, were recorded. EUS findings included location and size $(\mathrm{cm})$ of the pancreatic mass lesion, evidence of pancreatic duct (PD) and common bile duct (CBD) dilation ( $>7 \mathrm{~mm}$ ), vascular invasion of the tumour, the presence of malignant-appearing lymphadenopathy and metastasis. Also recorded was the number of FNA passes performed to make a cytological diagnosis.

Possible locations of lesions included the head, uncinate process, body and tail of the pancreas. PD dilation was defined as a PD diameter $>3 \mathrm{~mm}$ in the head, $2 \mathrm{~mm}$ in the body and $1 \mathrm{~mm}$ in the tail of the pancreas (7). If there was no mention of PD or CBD dilation in the EUS report, it was considered to be a negative finding. Vascular invasion was defined as the presence of tumour protruding into the vascular lumen as well as by vessel obstruction by tumour with or without the presence of collateral vessels $(8,9)$. Vascular invasion was also defined by an area $>15 \mathrm{~mm}$ of tumour-vessel interface without evidence of the echorich vascular wall. The presence of malignant-appearing lymphadenopathy was recorded if the four EUS features predictive of lymph node metastases were present: homogenous and hypoechoic appearance; sharply demarcated borders; rounded shape; and size $>10 \mathrm{~mm}$ (10).

\section{Statistical analysis}

The ability of each of the dichotomous variables to predict the probability of a patient having typical pancreatic cancer was assessed using logistic regression. In the case of malignant lymphadenopathy, the OR was not defined because of a zero in the $2 \times 2$ table. In this case, the association was tested using Fisher's exact test. $t$ tests were used to evaluate the differences between the means of the continuous variables of pancreatic adenocarcinoma and NPPA lesions.

\section{RESULTS}

Patient and lesion characteristics

A total of 230 patients were evaluated using EUS-FNA for suspected pancreatic mass lesions. Thirty-eight patients were excluded because they were diagnosed with inflammatory lesions or purely benign cysts. Of the 38 nonmalignant cases excluded, 18 lesions were purely benign nonmucinous cysts (pseudocysts [ $\mathrm{n}=10]$, simple cysts $[\mathrm{n}=2]$ and serous cystadenoma [n=4]), two were lymphopeithelial cysts and 18 lesions were inflammatory solid lesions (ie, chronic pancreatitis with mass effect [ $n=16]$ and autoimmune pancreatitis $[n=2]$ ).

There were 192 patients (101 male) diagnosed with either a pancreatic adenocarcinoma $(n=144)$ (Figures 1 A, 1B and 1C) or NPPA 

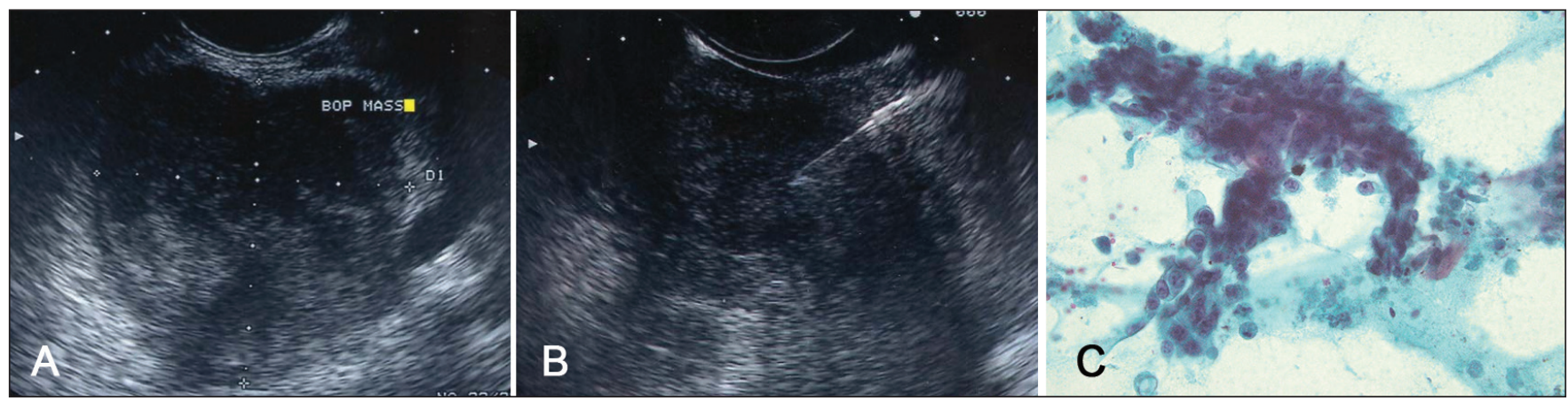

Figure 1) A Endoscopic ultrasound demonstrating a large, round, hypoechoic $4 \mathrm{~cm}$ mass lesion in the body of the pancreas with vascular invasion. B Endoscopic ultrasound demonstrating corresponding fine-needle aspiration technique with passage of 22-gauge fine-needle aspiration needle into the mass lesion. $\mathrm{C} C$ Corresponding cytopathology demonstrating primary pancreatic adenocarcinoma

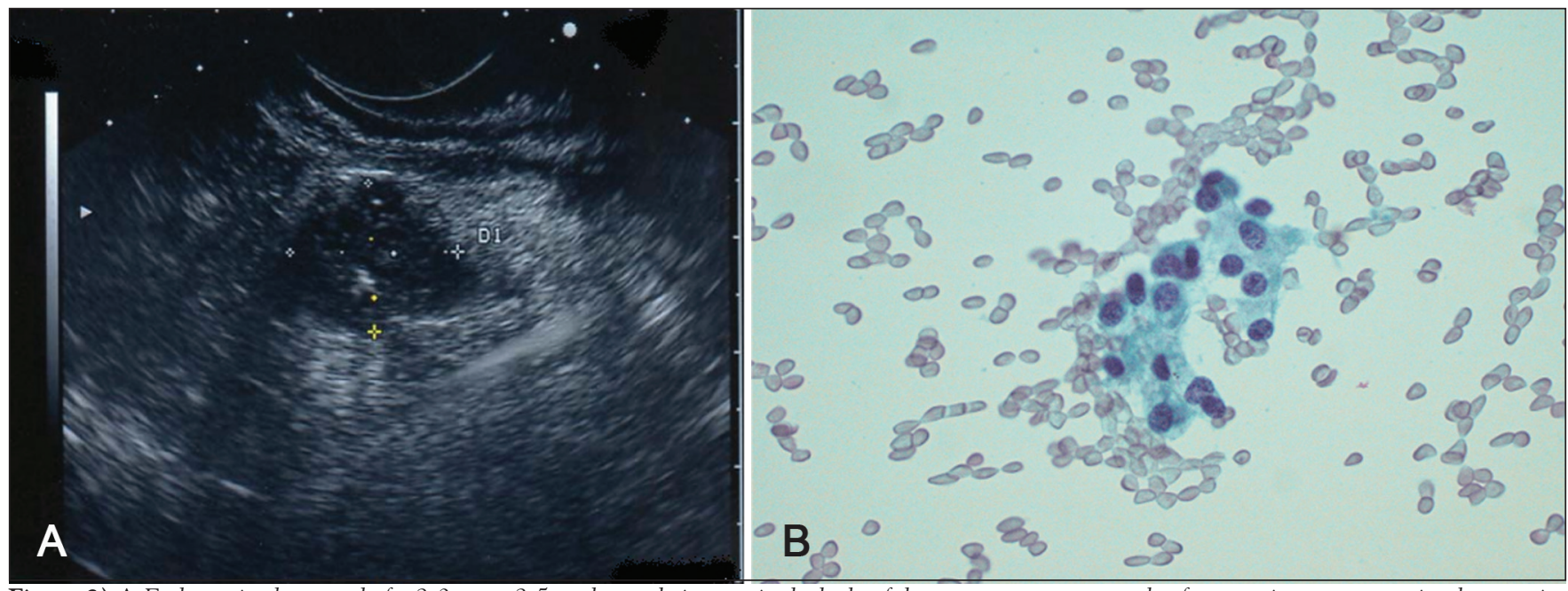

Figure 2) A Endoscopic ultrasound of a $2.0 \mathrm{~cm} \times 2.5 \mathrm{~cm}$ hypoechoic mass in the body of the pancreas as an example of a nonprimary pancreatic adenocarcinoma lesion. B Corresponding fine-needle aspiration cytology showing a cluster of cells with eccentrically placed (plasmacytoid) nuclei showing a 'salt and pepper' chromatin pattern that is present in this Papanicolaou-stained slide and consistent with an Islet cell (neuroendocrine) tumour

$(\mathrm{n}=48)$ over the five-year study period. The most common NPPA lesions diagnosed were neuroendocrine tumours $(n=18)$ (Figure 2, Table 1), followed by mucinous neoplasms with mixed solid/cystic components $(\mathrm{n}=12)$. In this subgroup, other primary pancreatic lesions included lymphoma $(n=4)$, solid/cystic pseudopapillary tumours $(n=2)$, gastrointestinal stromal tumour $(\mathrm{n}=1)$ and squamous cell carcinoma $(\mathrm{n}=1)$. The most common metastatic NPPA lesions were melanoma $(n=3)$ (Figure 3, Table 1) and small cell cancer $(n=3)$. Other rare, metastatic NPPA lesions included high-grade soft tissue sarcoma $(\mathrm{n}=2)$, papillary serous metastatic ovarian carcinoma $(\mathrm{n}=1)$ and breast cancer $(n=1)$. There were 21 patients $(11 \%)$ with initial FNA suspicious for malignancy who required a second attempt at tissue acquisition via repeat EUS-FNA, EUS-guided core biopsy or confirmed pathology based on surgical resection specimen. Of these 21 patients, 11 had confirmed NPPA neoplasms, while 10 had primary pancreatic adenocarcinoma.

Analysis of possible predictors

There were 144 patients ( 73 male [51\%]) with a mean age of 66 years, who were diagnosed with pancreatic adenocarcinoma and 48 patients (28 male [58\%]) with a mean age of 62.4 years, who were diagnosed with NPPA. When comparing primary adenocarcinomas with NPPAs, adenocarcinomas were more often located in the head of the pancreas $(\mathrm{n}=107$ [74\%]; OR 2.25; $\mathrm{P}=0.0198)$ and demonstrated more vascular invasion $(\mathrm{n}=71$ [50\%]; OR 4.37; $\mathrm{P}=0.0011)$. There was a significant difference in the presence of malignant lymphadenopathy ( $\mathrm{n}=36$ [39\%]; $\mathrm{P}=0.0006)$, $\mathrm{PD}$ dilation ( $\mathrm{n}=60$ [42\%]; OR 2.4; $\mathrm{P}=0.0220)$ and $\mathrm{CBD}$ dilation $(\mathrm{n}=36$ [25\%]; OR 2.87; $\mathrm{P}=0.0390)$ (Table 2).
TABLE 1

Diagnoses and percentage breakdown of nonprimary pancreatic adenocarcinoma $(n=48)$

\begin{tabular}{lc}
\hline Primary pancreatic & \\
Neuroendocrine tumours & $18(37.5)$ \\
Mucinous neoplasms with mixed solid/cystic components & $12(25)$ \\
Lymphoma & $4(8.2)$ \\
Solid/cystic pseudopapillary tumour & $2(4.2)$ \\
Gastrointestinal stromal tumour & $1(2.1)$ \\
Squamous cell carcinoma & $1(2.1)$ \\
Metastases to pancreas & \\
Melanoma & $3(6.25)$ \\
Small cell lung cancer & $3(6.25)$ \\
High-grade soft tissue sarcoma & $2(4.2)$ \\
Papillary serous/metastatic ovarian cancer & $1(2.1)$ \\
Breast cancer & $1(2.1)$ \\
\hline
\end{tabular}

Data presented as $n$ (\%)

NPPAs were commonly located in the head/uncinate process $(n=27[56 \%])$ but also were identified in the body $(n=13[27 \%])$ and tail $(n=10[21 \%])$. Fewer NPPA lesions demonstrated vascular invasion $(n=7[18 \%])$, PD dilation $(n=11[23 \%])$ and CBD dilation $(n=5[10 \%])$. No NPPA lesions presented with malignant lymphadenopathy (Table 2). 

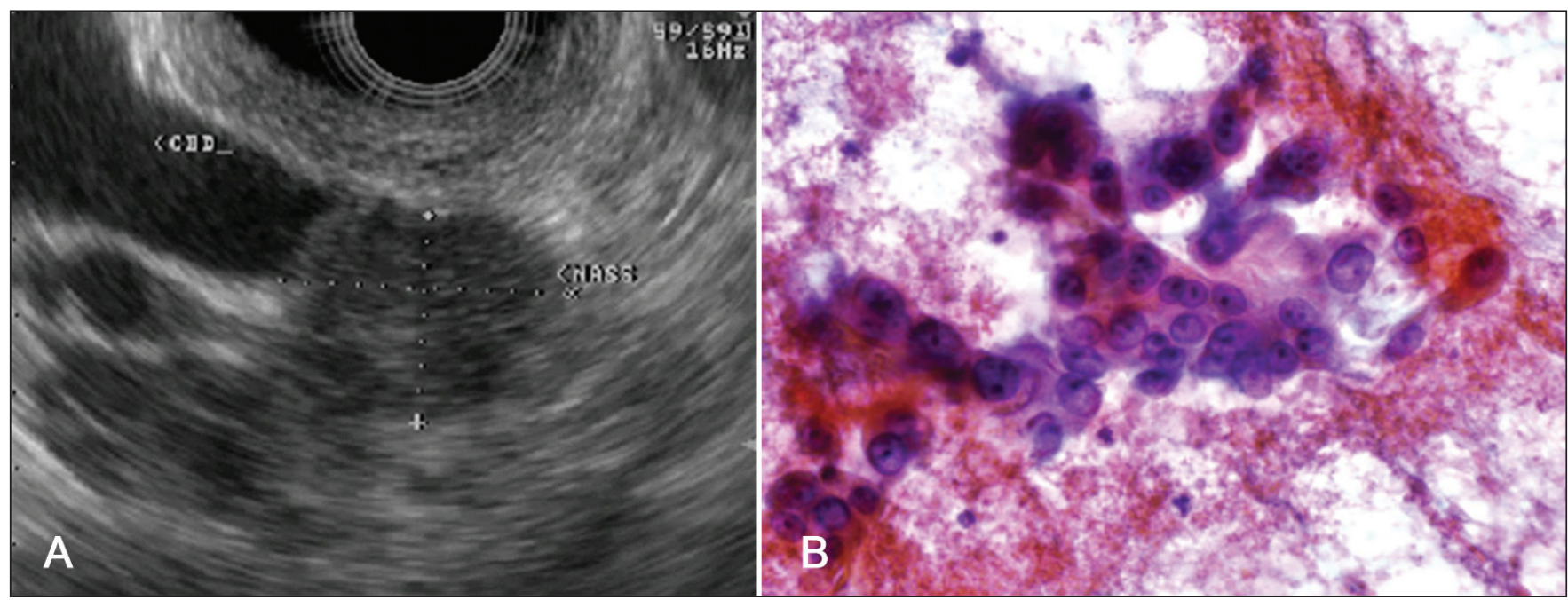

Figure 3) A Endoscopic ultrasound of a lesion located in the head of the pancreas with common bile duct invasion. The patient presented with obstructive jaundice. This mass is an example of a metastatic nonprimary pancreatic adenocarcinoma lesion. B Corresponding fine-needle aspiration cytology of melanoma. This Papanicolaou-stained slide shows a cluster of large cells with irregular nuclei and very prominent nucleoli. These findings are supportive of melanoma in the presence of additional immunohistochemically stained slides and in this particular patient with a history of scalp melanoma

TABLE 2

Comparison univariate analysis of nonprimary pancreatic adenocarcinoma (NPPA) versus primary pancreatic adenocarcinoma (ADENOCA)

\begin{tabular}{|c|c|c|c|c|}
\hline Variable & $\begin{array}{l}\text { ADENOCA } \\
(n=144)\end{array}$ & $\begin{array}{l}\text { NPPA } \\
(n=48)\end{array}$ & OR $(95 \% \mathrm{Cl})$ & $\mathbf{P}$ \\
\hline Age, years, mean & 66.1 & 62.44 & & 0.0675 \\
\hline Male sex & 73 (50.69) & $28(58.33)$ & $0.73(0.38-1.42)$ & 0.3595 \\
\hline Female sex & $71(49.31)$ & $20(41.67)$ & $1.36(0.7-2.64)$ & \\
\hline Lesion size, mm & $n=139$ & $n=48$ & & \\
\hline Mean & 34.88 & 36.83 & & 0.3801 \\
\hline$\geq 50$ & $6(4.32)$ & $11(22.92)$ & $0.15(0.05-0.44)$ & 0.0005 \\
\hline Location & $n=144$ & $n=48$ & & \\
\hline $\begin{array}{l}\text { Head of pancreas/ } \\
\text { uncinate process }\end{array}$ & $107(74.31)$ & $27(56.25)$ & $2.25(1.14-4.45)$ & 0.0198 \\
\hline Body of pancreas & $32(22.22)$ & $13(27.08)$ & 0.77 (0.36-1.63) & 0.4918 \\
\hline Tail of pancreas & $5(3.47)$ & $10(20.83)$ & $0.14(0.04-0.42)$ & 0.0006 \\
\hline VAS & $n=143$ & $n=38$ & & \\
\hline No & $72(50.35)$ & 31 (81.58) & $0.23(0.09-0.55)$ & 0.0011 \\
\hline Yes & $71(49.65)$ & $7(18.42)$ & 4.37 (1.81-10.56) & \\
\hline Lymph nodes & $n=143$ & $n=38$ & & \\
\hline NX & $51(35.66)$ & $20(52.63)$ & $0.5(0.24-1.03)$ & 0.0594 \\
\hline NO & $56(39.16)$ & $18(47.37)$ & $0.72(0.35-1.47)$ & 0.3615 \\
\hline N1 & $36(25.17)$ & $0(0)$ & NA & 0.9871 \\
\hline Metastasis & $n=143$ & $n=138$ & & \\
\hline $\mathrm{MX}$ & 131 (91.61) & 37 (97.37) & $0.3(0.04-2.34)$ & 0.2483 \\
\hline M1 & $12(8.39)$ & $1(2.63)$ & $3.39(0.43-26.92)$ & \\
\hline Ductal dilation & $n=144$ & $n=48$ & & \\
\hline Pancreatic duct & $60(41.67)$ & $11(22.92)$ & $2.4(1.13-5.09)$ & 0.0220 \\
\hline Common bile duct & $36(25)$ & $5(10.42)$ & $2.87(1.05-7.79)$ & 0.0390 \\
\hline $\begin{array}{l}\text { Lymph node, total } \\
\text { reviewed }\end{array}$ & $n=92$ & $n=18$ & & \\
\hline Malignant lymph node & $36(39.13)$ & $0(0)$ & NA & 0.0006 \\
\hline FNA passes & $n=139$ & $n=48$ & & \\
\hline $\mathrm{n}$, mean & 4.09 & 4.34 & & 0.3960 \\
\hline $\begin{array}{l}>3 \text { FNA passes for } \\
\text { diagnosis }\end{array}$ & $76(54.68)$ & $34(72.34)$ & $0.46(0.22-0.95)$ & 0.0354 \\
\hline
\end{tabular}

Data presented n (\%) unless otherwise indicated. FNA Fine-needle aspiration; VAS Vascular invasion
There was no significant difference in mean age $(\mathrm{P}=0.0675)$ or sex $(\mathrm{P}=0.3595)$ between patients who had adenocarcinoma versus NPPA. Similarly, overall average lesion size (adenocarcinoma $3.49 \mathrm{~cm}$ versus NPPA $3.68 \mathrm{~cm}$ ) was not significantly different by eventual diagnosis $(\mathrm{P}=0.3801)$. Nevertheless, larger lesions (ie, $>5 \mathrm{~cm}$ ) were often noted to be NPPA (11 of 48 [22.9\%]; $\mathrm{OR}=0.15 ; \mathrm{P}=0.0005$ ). Anatomically, adenocarcinomas were more likely to be located in the pancreatic head. Lesions located in the tail of the pancreas were more likely to be NPPA (OR 0.14; $\mathrm{P}=0.0006$ ). Lesions in the body of the pancreas had a clinically similar predilection for being primary adenocarcinoma (22.2\%) or NPPA (27.1.5\%) ( $\mathrm{P}=0.4918)$ (Table 2). Metastases were detected more frequently for adenocarcinoma $(n=12$ [8.4\%]; OR $3.39)$ versus NPPA ( $n=1[2.6 \%])$; however, this was not a statistically significant difference $(\mathrm{P}=0.2483)$.

There was no significant difference in the overall mean number of FNA passes that confirmed the diagnosis of primary pancreas adenocarcinoma (range one to five FNA passes) versus NPPA (range two to seven FNA passes); (4.09 versus 4.34; $\mathrm{P}=0.3960$ ). However, to establish a diagnosis of NPPA typically required more than three FNA passes (34 of 48 [72.3\%]; OR 0.46; $\mathrm{P}=0.0354$ ).

\section{DISCUSSION}

There is a paucity of literature defining specific EUS characteristics differentiating pancreatic adenocarcinoma from NPPA. Our findings suggest that patients with a diagnosis of adenocarcinoma were more likely to have lesions located in the pancreatic head, have vascular involvement, malignant-appearing lymphadenopathy, and PD and CBD dilation. This has been supported by other recent studies (11-15). The mean number of FNA passes performed for adequate diagnostic cytopathology of pancreatic lesions in our series was four (range one to seven), which is within the range of previously reported studies (three to seven) (16-17). PD and CBD dilation were more frequently present in our patients with adenocarcinoma. This can be attributed to the fact adenocarcinomas originate from the intraductal and acinar cells $(18,19)$. Based on univariate analysis, Rodriguez et al (7) found that PD and CBD dilation were also significant findings predictive of cancer.

Additionally, the mean size of the lesions was not significantly different between the two groups. A retrospective study of 1000 cases (20) revealed that EUS-FNA was more accurate than percutaneous FNA techniques for masses $<3 \mathrm{~cm}$ in size and that computed tomography and transabdominal ultrasound may not reliably detect pancreatic tumours $<3 \mathrm{~cm}$ in size. The reason to emphasize this is that a cut-off point of $3 \mathrm{~cm}$ is one of the variables shown to be a predictor of better 
outcome in patients with pancreatic cancer (21). Among our patients, $26.6 \%$ with adenocarcinoma had lesions $<3 \mathrm{~cm}$ in size. In these particular cases, early detection enables one to direct the clinical management of the patients and hopefully improve outcomes. Furthermore, larger lesions (ie, $>5.0 \mathrm{~cm}$ ) were more likely to be NPPA.

We excluded purely cystic lesions such as serous cystadenomas, simple cysts, lymphoepithelial cysts or pseudocysts. These are less likely to harbour an underlying malignancy than a solid or mixed solid/ cystic-appearing lesion on EUS. Additionally, due to the increasing risk of infection with every subsequent pass, usually only one FNA is performed for evaluating purely cystic lesions. Cytology yield is generally low for cystic lesions. Therefore, surgical resection to determine true pathology is inevitable when a malignant pancreatic neoplasm cannot be entirely excluded $(20,22)$.

Some authors have argued that a tissue diagnosis is unnecessary in patients with a sufficiently high clinical suspicion for cancer and, as such, the course of action should be surgical resection (23). We believe that the first step in management of the lesion is identification via FNA diagnosis. The lesions that yield a negative FNA can be further characterized by endosonographic features typical for adenocarcinoma versus NPPA lesions. This becomes particularly relevant in cases of NPPA, in which management is very different than in pancreatic cancer. For instance, patients with metastatic cancer to the pancreas have a very different approach to treatment, without any role for surgery, except for palliation. It our particular series, metastatic lesions accounted for $21 \%$ of the rare, atypical lesions.

The strength of our study was its unique approach to investigating EUS characteristics of solid and solid/cystic neoplasms as another method for diagnosis to be used with EUS-FNA. Imaoka et al (24) reviewed a large-centre experience examining the utility of EUSFNA and the prevalence of adenocarcinoma versus rare atypical lesions. They had 28 cases of rare (nonductal adenocarcinoma) pancreatic lesions. Of these, only 13 of 28 were defined malignant lesions (ie, pancreatic endocrine neoplasms, invasive intraductal papillary mucinous neoplasms), acinar cell canrcinoma, metastatic tumours and undifferentiated carcinoma with osteoclast-like giant cells); the other 15 were benign lesions. In our study, we reported 48 NPPA consisting of malignant solid and mixed solid/cystic pancreas lesions. According to our defined exclusion criteria, we would have eliminated the benign cases in their patient cohort. Nevertheless, their important study demonstrated that pancreatic neoplasms, other than ductal adenocarcinomas, have diverse imaging and histopathological features. In the study analysis by Imaoka et al (24), EUS-FNA correctly diagnosed the type of neoplasm in 19 cases $(67.9 \%)$ and distinguished between benign and malignant rare ('nonductal adenocarcinoma') tumours with a sensitivity of $69.2 \%$, a specificity of $100 \%$, a positive predictive value of $100 \%$, a negative predictive value of $79.0 \%$ and an overall accuracy of $85.7 \%$. Similar to our study, this suggests that EUS-FNS is accurate in distinguishing features of pancreas neoplasms. Therefore, this supports our assertion that EUS-FNA may assist to establish a diagnosis of NPPA.

Limitations of our study include its retrospective trial design. It was also a single-centre trial with a limited sample size. Given the fact that we are a tertiary care and oncology referral centre, there may be a component of selection bias accounting for the high number (ie, 26\%) of NPPAs. Most patients at our centre are referred by open-access endoscopy for EUS based on review of imaging studies and referral indications from their primary care physicians, or referring gastroenterologists, medical and surgical oncologists. Moreover, the present study was based on EUS-FNA findings, and we did not compare clinical presentation of symptoms between the two groups at the time of presentation. However, the strength of our trial is that there are limited data in the literature comparing the radiographic characteristics of atypical and typical pancreatic lesions. The information that we gained regarding the characteristics of adenocarcinoma appearance per EUS corroborates with existing literature and autopsy reports as elaborated above.
When EUS-FNA provides tissue that indicates malignancy, the positive predictive value is reported to be nearly $100 \%$ (25). The negative predictive value of EUS-FNA can be relatively low, ranging from $16 \%$ to $85 \%(1-3,25-28)$. A negative FNA cannot definitively rule out the presence of malignant disease. As many as one in 10 EUS-FNAs result in false-negative cytology (6). This is where the findings of our study can truly be used. Patients with features of having a lesion in the head of the pancreas, ductal dilation, as well as lymphatic and vascular involvement, are more likely to have an adenocarcinoma (6). At the same time, patients lacking these characteristics are more likely to have NPPA lesions, either benign or malignant, which may require a different management approach.

Nevertheless, FNA likely assists in the diagnosis of NPPA. As stated earlier in the Methods section, for the purposes of comparing FNA passes and diagnostic yield in patients with primary pancreas adenocarcinoma versus NPPA, we restricted the study cohort to patients who had an FNA diagnosis that was definitively positive or suspicious for malignancy. In an earlier article from our institution by Spier et al (6), which investigated predictors of malignancy in the setting of a negative EUS-FNA, 17 of 55 patients (31\%) with an initial negative/nondiagnostic FNA were subsequently diagnosed with pancreatic adenocarcinoma, with a mean time to diagnosis of 66 days from the initial false-negative FNA. However, in this group, none of these patients were diagnosed with other NPPAs. The true-negative FNA patients were followed for a mean of 403 days without the development of pancreatic malignancy. However, in this study, the patients who initially had a negative or nondiagnostic FNA, but were subsequently diagnosed with pancreatic malignancy, had a significantly increased risk of cancer in the setting of lymphadenopathy $(\mathrm{P}<0.001)$ and suspected vascular invasion/involvement $(\mathrm{P}<0.001)$. Therefore, these serve as strong positive predictors for adenocarcinoma. This was also reflected in the current study.

In this light, a recent study by Turner et al (29) evaluated the accuracy of EUS-FNA in the diagnosis of pancreatic neoplasia. EUSFNA was found to be $80 \%$ accurate for the detection of pancreatic adenocarcinoma using aspiration cytology. However, reclassification of suspicious cytology samples as diagnostic of malignancy resulted in a sensitivity of $93 \%$ for adenocarcinomas and $80 \%$ for pancreatic neuroendocrine tumours, with an overall improved accuracy rate of 94\% (29). In our retrospective cohort, initial EUS-FNA made the diagnosis of adenocarcinoma or NPPA in $90 \%$ of cases given strict cytological criteria, thus reflecting a very good accuracy rate. In approximately $11 \%$ of these cases ( 21 of 192 patients) that were interpreted as 'suspicious' for malignancy, 11 had confirmed NPPA based on repeat EUS-FNA, EUS-guided core biopsy or definitive pathology based on a surgical resection specimen.

Pancreatic mass lesions and tissue characterization may also be improved by the newer generation of endosonographic processers that use elastography. A recent study by Itokawa et al (30) demonstrated that EUS elastography with semiquantitative analysis using the strain ratio was helpful in differentiating various mass lesions of the pancreas. In their retrospective analysis of 109 patients, they were able to accurately distinguish between mass-forming pancreatitis versus pancreatic cancer. However, a study by Hirch et al (31) noted that the main limitation of EUS elastography in evaluating mass lesions of the pancreas was incomplete delineation of the border of lesions $\geq 35 \mathrm{~mm}$ in diameter or lesions at some distance from the transducer. They also noted that eleastographic recordings were hampered by the fact that the surrounding tissue was inadequately displayed in the larger mass lesions and this would impact on the strain ratio calculation. In this prospective study of 70 patients, they found that EUS elastography predicted the nature of pancreatic lesions with poor diagnostic sensitivity (41\%), specificity (53\%) and accuracy (45\%). As a result, the authors concluded that the clinical utility of this technique remains questionable and it seems that the information provided would unlikely obviate the need for obtaining tissue samples via FNA for confirmation of a final pathological diagnosis. 
Our study is one of the first to describe endosonographic features in addition to FNA cytopathology as a way to improve the accuracy of EUS and better characterize the findings as applicable to other NPPA lesions. The implications of the present study are that EUS-FNA may help in delineating the nature of pancreatic lesions and, therefore, may help in management. Moreover, among the NPPA lesions, there are a variety of lesions in which the treatment differs considerably for the individual subtype within the group (ie, lymphoma versus squamous cell carcinoma). Through our study, we hope to encourage other large tertiary multicentre studies to compare EUS features with FNA cytopathological analysis.

\section{KEY MESSAGES}

1. EUS-FNA features can help distinguish malignant pancreas neoplasms including differentiating between primary adenocarcinoma and NPPA lesions.

2. EUS characterestics that accurately help to diagnose primary pancreas adenocarcinoma include location of the mass lesion in the head of the pancreas, the presence of vascular invasion, malignant lymphadenopathy, PD dilation and CBD dilation. Lesions located in the tail of the pancreas, larger size lesions (ie, $>5 \mathrm{~cm}$ ) and lesions that require more than three FNA passes to establish a diagnosis are more often NPPA.

3. In our study, $25 \%$ of malignant pancreatic neoplasms were NPPA, suggesting that EUS-FNA is essential in establishing a diagnosis and may be helpful in clinical decision making.

DISCLOSURES: The authors have no financial disclosures or conflicts of interest to declare.

\section{REFERENCES}

1. Eloubeidi MA, Jhala D, Chhieng DC, et al. Yield of endoscopic ultrasound-guided fine-needle aspiration biopsy in patients with suspected pancreatic carcinoma. Cancer 2003;99:285-92.

2. Harewood GC, Wiersema MJ. Endosonography-guided fine needle aspiration biopsy in the evaluation of pancreatic masses.

Am J Gastroenterol 2002;97:1386-91.

3. Raut CP, Grau AM, Staerkel GA, et al. Diagnostic accuracy of endoscopic ultrasound-guided fine-needle aspiration in patients with presumed pancreatic cancer. J Gastrointest Surg 2003;7:118-26; discussion 27-8.

4. Gress F, Gottlieb K, Sherman S, Lehman G. Endoscopic ultrasonography-guided fine-needle aspiration biopsy of suspected pancreatic cancer. Ann Intern Med 2001;134:459-64.

5. Rosewicz S, Wiedenmann B. Pancreatic carcinoma. Lancet 1997;349:485-9.

6. Spier BJ, Johnson EA, Gopal DV, et al. Predictors of malignancy and recommended follow-up in patients with negative endoscopic ultrasound-guided fine-needle aspiration of suspected pancreatic lesions. Can J Gastroenterol 2009;23:279-86.

7. Rodriguez S, Faigel D. Absence of a dilated duct predicts benign disease in suspected pancreas cancer: A simple clinical rule. Dig Dis Sci 2010;55:1161-6.

8. Rösch T, Dittler HJ, Strobel K, et al. Endoscopic ultrasound criteria for vascular invasion in the staging of cancer of the head of the pancreas: A blind reevaluation of videotapes. Gastrointest Endosc 2000;52:469-77.

9. Brugge WR, Lee MJ, Kelsey PB, Schapiro RH, Warshaw AL. The use of EUS to diagnose malignant portal venous system invasion by pancreatic cancer. Gastrointest Endosc 1996;43:561-7.

10. Catalano MF, Sivak MV Jr, Rice T, Gragg LA, Van Dam J. Endosonographic features predictive of lymph node metastasis. Gastrointest Endosc 1994;40:442-6.
11. Töx U, Hackenberg R, Stelzer A, et al. Endosonographic diagnosis of solid pancreatic tumors: A retrospective analysis from a tertiary referral center. Gastroenterology 2007;45:307-12.

12. Varadarajulu S, Tamhane A, Eloubeidi MA. Yield of EUS-guided FNA of pancreatic masses in the presence or the absence of chronic pancreatitis. Gastrointest Endosc 2005;62:728-36, quiz 51,53.

13. Harewood GC, Wiersema MJ. Endosonography-guided fine needle aspiration biopsy in the evaluation of pancreatic masses. Am J Gastroenterol 2002;97:1386-91.

14. Wakatsuki T, Irisawa A, Bhutani MS, Hikichi T, Shibukawa G, Takagi T. Comparative study of diagnostic value of cytologic sampling by endoscopic ultrasonography-guided fine-needle aspiration and that by endoscopic retrograde pancreatography for the management of pancreatic mass without biliary stricture. J Gastroenterol Hepatol 2005;20:1707-11.

15. Horwhat JD, Paulson EK, McGrath K, et al. A randomized comparison of EUS-guided FNA versus CT or US-guided FNA for the evaluation of pancreatic mass lesions. Gastrointest Endosc 2006;63:966-75.

16. LeBlanc JK, Ciaccia D, Al-Assi MT, et al. Optimal number of EUS-guided fine needle passes needed to obtain a correct diagnosis. Gastrointest Endosc 2004;59:475-81.

17. Eloubeidi MA, Tamhane A. EUS-guided FNA of solid pancreatic masses: A learning curve with 300 consecutive procedures. Gastrointest Endosc 2005;61:700-8.

18. Moskaluk CA, Kern SE. Molecular genetics of pancreatic cancer. In: Reber HA, ed. Pancreatic Cancer. Totowa: Humana Press; 1998:3-20

19. Jimenez RE, Fernandez-del Castillo C. Tumors of the pancreas. In: Feldman M, Scharschmidt BF , Sleisenger MH, Fordtran, JS. In: Sleisenger and Fordtran's Gastrointestinal and Liver Disease. Pathophysiology/diagnosis/management. Philadelphia: Elsevier Health Sciences, 2010:1131.

20. Volmar KE,Vollmer RT, Jowell PS, Nelson RC, Xie HB. Pancreatic FNA in 1000 cases: A comparison of imaging modalities. Gastrointest Endosc 2005;61:854-1.

21. Sohn TA, Yeo CJ, Cameron JL, et al. Resected adenocarcinoma of the pancreas-616 patients: Results, outcomes, and prognostic indicators. J Gastrointest Surg 2000;4:567-79.

22. Capitanich P, Iovaldi ML, Medrano M, et al. Lymphoepithelial cysts of the pancreas: Case report and review of the literature. J Gastrointest Surg 2004;8:342-5.

23. Cooperman A, Fader A, Cushin B, et al. Surgery and cancer of the pancreas: Will common sense become common practice? Hematol Oncol Clin N Am 2002;16:81-94.

24. Imaoka H, Yamao K, Bhatia V, et al. Rare pancreatic neoplasms: The utility of endoscopic ultrasound-guided fine-needle aspiration a large single center study. J Gastroenterol 2009;44:146-53.

25. Agarwal B, Abu-Hamda E, Molke KL, Correa AM, Ho L. Endoscopic ultrasound-guided fine needle aspiration and multidetector spiral CT in the diagnosis of pancreatic cancer. Am J Gastroenterol 2004;99:844-50.

26. Williams DB, Sahai AV, Aabakken L, et al. Endoscopic ultrasound guided fine needle aspiration biopsy: A large single centre experience. Gut 1999;44:720-6.

27. Bhutani MS, Hawes RH, Baron PL, et al. Endoscopic ultrasound guided fine needle aspiration of malignant pancreatic lesions. Endoscopy 1997;29:854-8.

28. Voss M, Hammel P, Molas G, Palazzo L, Dancour A, O’Toole D. Value of endoscopic ultrasound guided fine needle aspiration biopsy in the diagnosis of solid pancreatic masses. Gut 2000;46:244.

29. Turner BG, Cizginer S, Agarwal D, Yang J, Pitman MB, Brugge WR. Diagnosis of pancreatic neoplasia with EUS and FNA: A report of accuracy. Gastrointest Endosc 2010;71:91-8.

30. Itokawa F, Itoi T, Sofuni A, et al. EUS elastography combined with strain ratio of tissue elasticity for diagnosis of solid pancreatic masses. J Gastroenterol 2011;46:843-53.

31. Hirch TO, Ignee A, Barreiros AP, et al. Indications and limitations of endoscopic ultrasound elastography for evaluation of focal pancreatic lesions. Endoscopy 2008;40:910-7. 


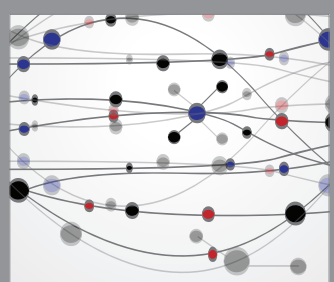

The Scientific World Journal
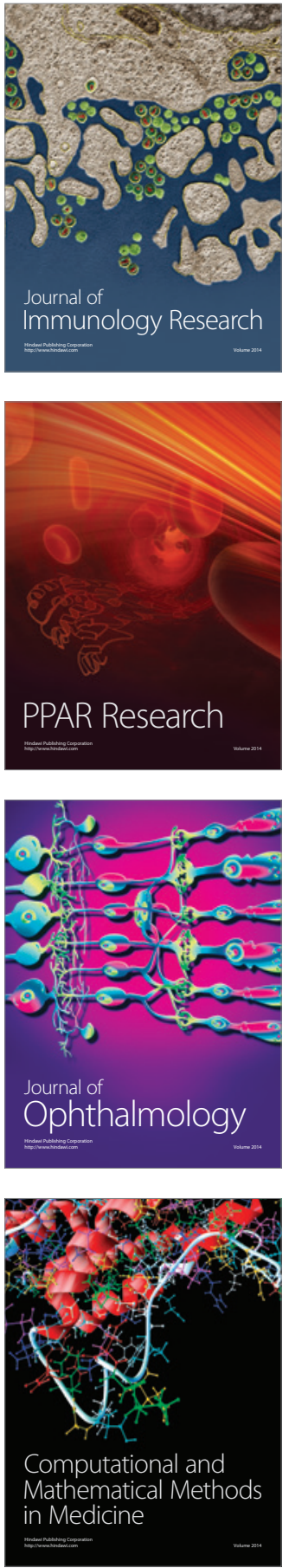

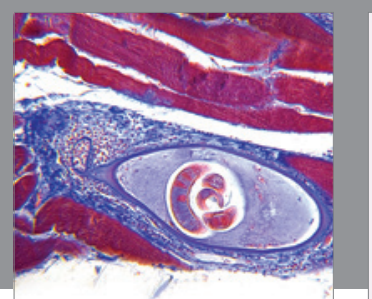

Gastroenterology Research and Practice

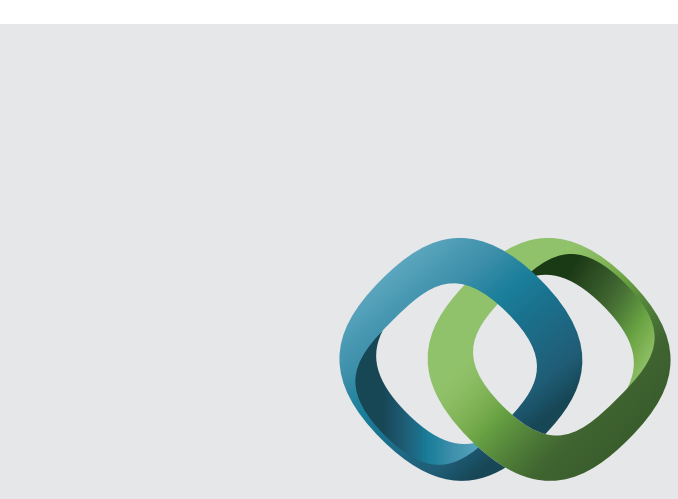

\section{Hindawi}

Submit your manuscripts at

http://www.hindawi.com
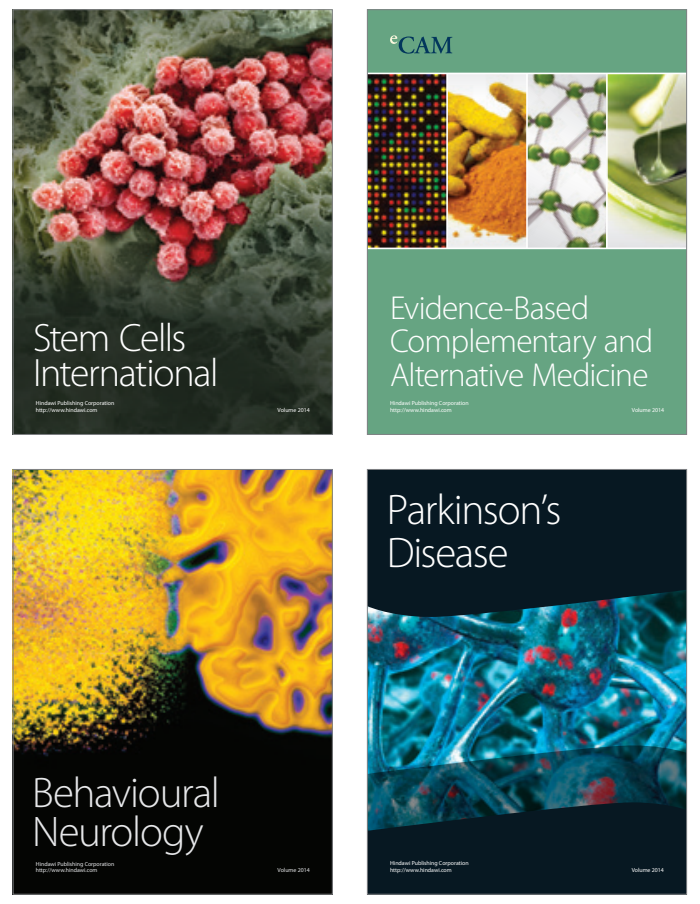
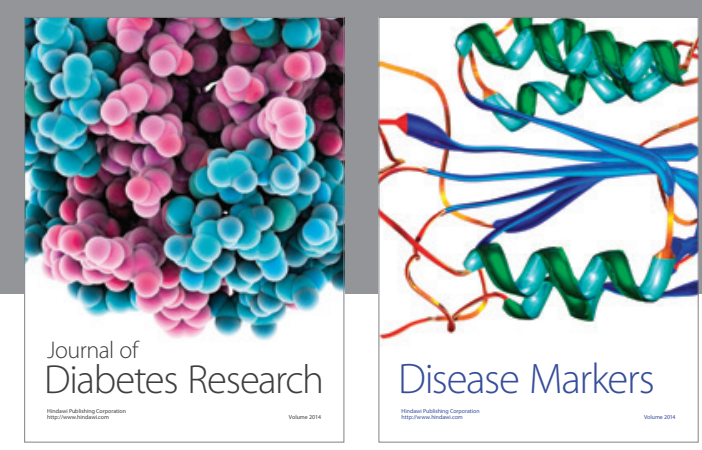

Disease Markers
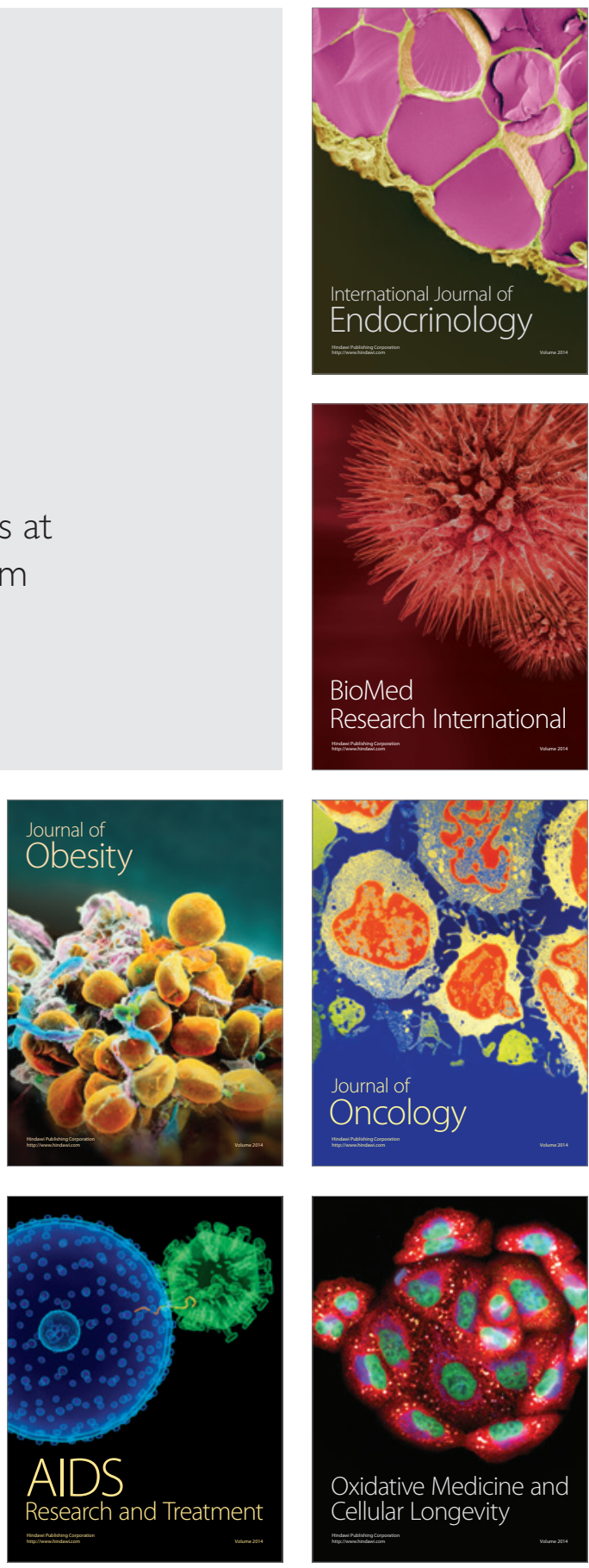